\title{
Human Fatty Acid Synthesis Is Stimulated by a Eucaloric Low Fat, High Carbohydrate Diet
}

\author{
Lisa Cooper Hudgins, ${ }^{\star}$ Marc Hellerstein, ${ }^{\ddagger}$ Cynthia Seidman, ${ }^{\star}$ Richard Neese, ${ }^{\ddagger}$ Jolanta Diakun, ${ }^{\star}$ and Jules Hirsch \\ *The Rockefeller University, New York 10021; and ${ }^{\ddagger}$ Department of Nutritional Sciences, University of California, Berkeley, California \\ 94720 and Division of Endocrinology and Metabolism, Department of Medicine, University of California, San Francisco, California \\ 94110
}

\begin{abstract}
A new experimental approach was used to determine whether a eucaloric, low fat, high carbohydrate diet increases fatty acid synthesis. Normal volunteers consumed low fat liquid formula diets $(\mathbf{1 0 \%}$ of calories as fat and $\mathbf{7 5 \%}$ as glucose polymers, $n=7)$ or high fat diets $(40 \%$ of calories as fat and $45 \%$ as glucose polymers, $n=3$ ) for $25 \mathrm{~d}$. The fatty acid composition of each diet was matched to the composition of each subject's adipose tissue and compared with the composition of VLDL triglyceride. By day 10, VLDL triglyceride was markedly enriched in palmitate and deficient in linoleate in all subjects on the low fat diet. Newly synthesized fatty acids accounted for $44 \pm 10 \%$ of the VLDL triglyceride. Mass isotopomer distribution analysis of palmitate labeled with intravenously infused ${ }^{13} \mathrm{C}$-acetate confirmed that increased palmitate synthesis was the likely cause for the accumulation of triglyceride palmitate and "dilution" of linoleate. In contrast, there was minimal fatty acid synthesis on the high fat diet. Thus, the dietary substitution of carbohydrate for fat stimulated fatty acid synthesis and the plasma accumulation of palmitate-enriched, linoleate-deficient triglyceride. Such changes could have adverse effects on the cardiovascular system. (J. Clin. Invest. 1996. 97:2081-2091.) Key words: fatty acids • triglycerides • palmitic acids • linoleic acids • very low density lipoproteins
\end{abstract}

\section{Introduction}

It is generally thought that the biosynthesis of fatty acids is an unimportant metabolic pathway in weight-stable human subjects. However, most previous studies have been limited to in vitro incubations of surgically excised liver, adipose tissue, or intestine from individuals consuming average levels of fat (1-4). It is well known that fatty acid synthesis is stimulated by low fat, high carbohydrate diets in animals which are normally in

This study was presented in abstract form at the October 1993 meeting of the North American Society for the Study of Obesity (1993. Obesity Research. 1:925a) and at the November 1993 meeting of the American Heart Association (1993. Circulation. 88:I317a).

Address correspondence to Lisa Cooper Hudgins, M.D., Laboratory of Human Behavior and Metabolism, The Rockefeller University, 1230 York Avenue, New York, NY 10021. Phone: 212-327-7744; FAX: 212-327-7150; E-mail: hudgins@rockvax.rockefeller.edu

Received for publication 6 December 1995 and accepted in revised form 9 February 1996.

J. Clin. Invest.

(c) The American Society for Clinical Investigation, Inc.

0021-9738/96/05/2081/11 \$2.00

Volume 97, Number 9, May 1996, 2081-2091 positive caloric balance $(5,6)$. Furthermore, substantial net total body fatty acid synthesis $(>150$ grams/d) and fat storage were demonstrated using indirect calorimetry in normal human volunteers who consumed very high calorie, low fat, high carbohydrate diets for several days (7). However, the techniques of indirect calorimetry will only detect fatty acid synthesis in excess of oxidation, and they cannot be used to study dietary effects on fatty acid synthesis when caloric intake and expenditure are in balance.

Recently, new isotopic methods to study human fatty acid synthesis in vivo were developed that measure the incorporation of either ${ }^{13} \mathrm{C}$-acetate or deuterated water into plasma fatty acids (8-10). The results of both methods have confirmed the conclusions of the in vitro studies and indicate minimal fatty acid synthesis after an overnight fast in normal volunteers who had consumed diets with average fat content. A single day of high carbohydrate intake as a constant intravenous infusion of glucose, hourly liquid meals, or a high carbohydrate breakfast increased the fraction of de novo VLDL palmitate from 1 to $5 \%$ in males and from 4 to $10 \%$ in females $(8,11)$. This represents a maximum of only 2.5 grams palmitate/d, based on an estimated VLDL triglyceride (TG) ${ }^{1}$ secretion rate of 25 grams/d. However, the de novo lipogenic response to eucaloric low fat, high carbohydrate diets consumed for more prolonged periods of time is unknown.

Such observations are of importance because of public health recommendations to markedly reduce dietary fat and to increase dietary carbohydrate. Increased fatty acid synthesis could have two major adverse effects on cardiovascular health. First, an increase in de novo fatty acids may stimulate hepatic TG synthesis, secretion, and plasma TG concentrations (12, 13). Secondly, since the fatty acid preferentially formed by mammalian fatty acid synthase, palmitate (16:0), is a saturated fatty acid $(1,14)$, the composition of TG and other esterified lipids in the plasma and other tissues may be enriched in saturated fatty acids and depleted in essential, polyunsaturated fatty acids that cannot be synthesized de novo. Increased plasma TG (15) and reduced plasma or tissue polyunsaturated fatty acids $(16,17)$ have both been associated with an increased risk of cardiovascular disease.

In this paper, we describe a new experimental approach to measure fatty acid synthesis in vivo in humans. It is based on the model that fatty acids in VLDL TG are a mixture derived without fatty acid selection from three major sources: dietary fat, adipose tissue, and de novo synthesis. Only two sources, the diet and adipose tissue, provide linoleate (18:2), since it cannot be synthesized by the body. When the proportion of 18:2 in the diet is matched to the proportion of 18:2 in the adipose tis-

1. Abbreviations used in this paper: GCMS, gas chromatography-mass spectrometry; HDL-C, HDL cholesterol; MIDA, mass isotopomer distribution analysis; REE, resting energy expenditure; TG, triglyceride. 
sue, then the proportion of 18:2 in VLDL TG becomes an index of the fraction of preformed fatty acids from the diet and adipose tissue. The fraction of de novo fatty acids, or the dilution of 18:2 in VLDL TG below the level in the diet and adipose tissue, is a measure of newly synthesized fatty acids.

The purpose of this investigation was to test the validity of the method and to answer two major questions. First, is fatty acid synthesis minimal on a high fat diet, as indicated by the same levels of 18:2 in VLDL TG, in the diet and in the adipose tissue? Second, is fatty acid synthesis increased on a low fat diet, as indicated by a lower level of 18:2 in VLDL TG than in the diet and adipose tissue? In the controlled environment of The Rockefeller University Clinical Research Center, normal volunteers consumed weight-maintaining diets that differed in the relative amounts of fat and carbohydrate. As required by the method, the fatty acid composition of each diet was matched to each subject's adipose tissue. At the end of each 25-d dietary period, the level of 18:2 in VLDL TG was measured, as well as the fractional synthesis of VLDL TG 16:0 from the incorporation of ${ }^{13} \mathrm{C}$-acetate and mass isotopomer distribution analysis (MIDA) (9).

\section{Methods}

Subjects. The characteristics of the subjects are shown in Table I. Seven subjects received low fat diet A, and three subjects received high fat diet B. All were healthy nonsmokers on no oral prescription medications and from a variety of racial and ethnic backgrounds. Body weights were between 80 and $120 \%$ ideal body weight and were stable within $10 \%$ of the weight at admission for the previous 6 mo. The waist circumferences at the umbilicus and the widest hip circumferences were measured to the nearest millimeter. The plasma TG, cholesterol, and HDL cholesterol (HDL-C) levels in Table I are the means of two to three values obtained after 12-h overnight fasts on admission and on outpatient visits within 2 mo of admission. The lipid profiles were normal except for an elevated HDL-C $(2.41 \mathrm{mM})$ in subject 2 . All studies were approved by The Rockefeller University
Institutional Review Board, and informed consent was obtained from all participating subjects.

Diets. Liquid formula diets of exactly known composition that differed in the ratio of fat to carbohydrate were consumed for $25 \mathrm{~d}$. Table II shows the composition of the tested diets. Low fat diet A was $10 \%$ fat, $75 \%$ carbohydrate; high fat diet B was $40 \%$ fat, $45 \%$ carbohydrate. The fatty acid compositions of the diets were closely matched to the fatty acid composition of each subject's adipose tissue by mixing lard, olive oil, and corn oil. The mean fatty acid compositions of the low fat and high fat diets were similar, as shown in Table II. The \%18:2 (10-23\%) spanned the normal population range and met the essential fatty acid requirement of at least $1 \%$ of total calories. The carbohydrate source was glucose polymers with an average polymer size of five glucose molecules (Polycose; Ross Laboratories, Columbus, $\mathrm{OH}$ ). The protein source was milk protein (Casec; Mead Johnson, Evansville, IN). Cholesterol was added with adjustments made for the cholesterol in lard and milk protein to total $200 \mathrm{mg} / \mathrm{d}$. All diets were equally supplemented with sodium chloride (5 grams/d), multivitamins, and iron.

The total calories in each diet were adjusted to maintain constant weight. The initial number of calories was $1,360 \mathrm{kcal} / \mathrm{m}^{2}$ of surface area, a constant found to be the average need with the level of physical activity on the research unit. Minimal adjustment of total calories $(< \pm 200 \mathrm{kcal} / \mathrm{d})$ was required to maintain weight within $0.5 \mathrm{~kg}$. The slopes of the regression lines of the weights in the last $2 \mathrm{wk}$ were not significantly different from zero, except for subject 5 who gained 0.56 $\mathrm{kg}$ during this period. The diets, given in five equal servings, were consumed within $1 / 2 \mathrm{~h}$ every $2-3 \mathrm{~h}$ between 8:00 a.m. and 8:00 p.m., except on the days of the ${ }^{13} \mathrm{C}$-acetate studies, when meal time was standardized to 9:00 a.m., 11:00 a.m., 1:00 p.m., 3:00 p.m., and 5:00 p.m. All diets were well tolerated.

Gas chromatographic analysis of the total fat and fatty acid compositions of the lipid ( $>95 \% \mathrm{TG}$ ) from samples of formula closely matched desired values. The total calories per gram of homogenate measured by bomb calorimetry came within $5 \%$ of expected values $(1.25 \mathrm{kcal} / \mathrm{gram})$.

Nonisotopic linoleate dilution method. This method is based on the model that the fatty acid composition of VLDL TG is determined by the relative input of fatty acids from the diet, the adipose tissue, and endogenous de novo synthesis (Fig. 1). When the fatty acid composition of the tested diet is closely matched to the composition of the

Table I. Subject Characteristics

\begin{tabular}{|c|c|c|c|c|c|c|c|}
\hline Subject & Age & Sex & BMI* & $\mathrm{W} / \mathrm{H}^{\ddagger}$ & TG & CHOL & HDL-C \\
\hline & $y r$ & & $\mathrm{~kg} / \mathrm{m}^{2}$ & & $m M$ & $m M$ & $m M$ \\
\hline \multicolumn{8}{|l|}{ Low fat diet A } \\
\hline 1 & 23 & M & 28.0 & 0.96 & 0.83 & 4.13 & 1.08 \\
\hline 2 & 20 & $\mathrm{~F}$ & 19.1 & 0.75 & 0.68 & 4.26 & 2.41 \\
\hline 3 & 22 & M & 20.7 & 0.81 & 0.77 & 3.85 & 0.92 \\
\hline 4 & 20 & $\mathrm{~F}$ & 19.7 & 0.75 & 1.49 & 4.56 & 1.13 \\
\hline 5 & 24 & $\mathrm{~F}$ & 20.6 & 0.80 & 0.67 & 4.03 & 1.36 \\
\hline 6 & 20 & M & 20.0 & 0.82 & 0.61 & 4.21 & 1.46 \\
\hline 7 & 20 & M & 21.5 & 0.82 & 0.93 & 3.59 & 0.87 \\
\hline Mean & 21 & & 21.4 & 0.82 & 0.86 & 4.09 & 1.32 \\
\hline $\mathrm{SD}$ & 2 & & 3.0 & 0.07 & 0.30 & 0.31 & 0.53 \\
\hline \multicolumn{8}{|l|}{ High fat diet B } \\
\hline 8 & 57 & M & 28.8 & 1.04 & 1.28 & 4.79 & 0.90 \\
\hline 9 & 27 & M & 22.4 & 0.84 & 0.94 & 3.82 & 1.51 \\
\hline 10 & 24 & $\mathrm{~F}$ & 24.5 & 0.83 & 0.75 & 4.56 & 1.28 \\
\hline Mean & 36 & & 25.2 & 0.90 & 0.99 & 4.39 & 1.23 \\
\hline $\mathrm{SD}$ & 18 & & 3.3 & 0.12 & 0.27 & 0.51 & 0.31 \\
\hline
\end{tabular}

*Body mass index; ${ }^{\ddagger}$ Waist circumference-to-hip circumference ratio. 
Table II. Composition of Diets

\begin{tabular}{lcc}
\hline & Diet A & Diet B \\
\hline \%Protein & 15 & 15 \\
\%Carbohydrate* & 75 & 45 \\
\%Fat & 10 & 40 \\
Fatty acid composition & & \\
\%16:0 & 19 & 18 \\
$\% 18: 0$ & 12 & 11 \\
$\% 18: 1$ & 40 & 40 \\
$\% 18: 2$ & 15 & 18
\end{tabular}

* Glucose polymers; ${ }^{\ddagger}$ Fatty acid composition matched to each subject's adipose tissue; mean percentages for major fatty acids given below; cholesterol $=200 \mathrm{mg} / \mathrm{d}$.

adipose tissue and there is minimal selectivity in the metabolism of the major fatty acids, then 18:2 in VLDL TG can be used as a marker for the fractional input of preformed fatty acids from the diet and/or adipose tissue, as opposed to de novo synthesis.

Fig. 1 shows the expected \%18:2 in VLDL TG at increasing levels of de novo fatty acids when the \%18:2 in the diet and adipose tissue are both $20 \%$. When there are no de novo fatty acids, the \%18:2 in VLDL TG equals the percentage in the diet and adipose tissue in a ratio of $1: 1$ (e.g., $20 \%: 20 \%$ ). Alternatively, when all of the fatty acids
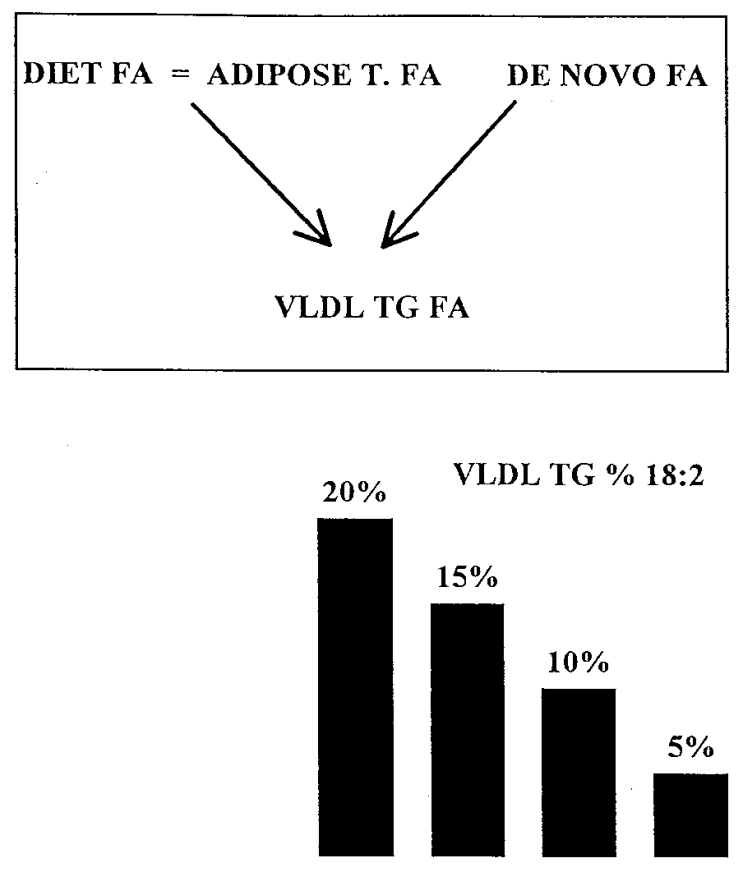

$0 \%$

VLDL TG FA

\begin{tabular}{lrrrrr}
\hline$\%$ De Novo & $0 \%$ & $25 \%$ & $50 \%$ & $75 \%$ & $100 \%$ \\
$\begin{array}{l}\% \text { Preformed } \\
\text { (Diet-AT) }\end{array}$ & $100 \%$ & $75 \%$ & $50 \%$ & $25 \%$ & $0 \%$
\end{tabular}

Figure 1. Model of the linoleate dilution method to measure fatty acid synthesis. The fatty acid compositions of the diet and adipose tissue are matched, and the fractional input of preformed and de novo fatty acids is calculated from the decrease, or dilution, of 18:2 in VLDL TG below the concentration in the diet and adipose tissue. are formed de novo, then there is no 18:2 in VLDL TG. If there are contributions from both sources, then the \%18:2 in VLDL TG decreases below the percentage in the diet and adipose tissue to a ratio $<1: 1$. This ratio equals the fraction of preformed fatty acids from the diet-adipose tissue, and the remainder equals the fraction of VLDL TG that is formed de novo:

Percent de novo VLDL TG $=($ diet-adipose tissue $\% 18: 2-$ VLDL TG $\% 18: 2) \times 100 /$ diet-adipose tissue $\% 18: 2$.

The method assumes that $(a)$ the fatty acid composition of adipose tissue will not change in the course of a 1-2-mo study because of the extremely slow turnover of the large pool of stored TG and $(b)$ the fraction of de novo VLDL TG fatty acids reflects the absolute rate of fatty acid synthesis. The method is validated when combined with direct measurements of fatty acid synthesis using isotopic precursors to distinguish between changes in the plasma input of de novo fatty acids versus selective metabolism of fatty acids.

Isotopic method: MIDA. Fatty acid synthesis was independently measured at the end of each diet by the intravenous infusion of ${ }^{13} \mathrm{C}$ acetate and application of the MIDA technique $(8,9)$. In brief, this method uses probability analysis to measure the synthesis of biological polymers. It is based on the mathematical principle that the labeling pattern of a polymer synthesized from a stable-isotopically labeled precursor will conform to a predicted binomial or multinomial expansion. Thus, the isotopic enrichment of the precursor pool(s) is calculated from measurements on the product alone. In the case of fatty acid synthesis, the proportions of excess (above natural background abundance) single-labeled and double-labeled 16:0 (EM1 and EM2 species, respectively) are a function of the probability $(P)$ that the precursor subunits were isotopically labeled. Using this value of $P$ for the isotopic enrichment of the acetyl CoA pool, the theoretical ${ }^{13} \mathrm{C}$ enrichment in $16: 0$ if $100 \%$ of the $16: 0$ were newly formed from this acetate pool is calculated. The actual isotopic enrichment is measured by gas chromatography-mass spectrometry (GCMS). This value divided by the theoretical maximum value equals the fraction of 16:0 that is newly formed (f). The value for $f$ represents dilution of de novo synthesized 16:0 by non-de novo sources.

This method requires that newly synthesized (labeled) and preformed (unlabeled) 16:0 $\mathrm{mix}$ in the liver and communicate with plasma VLDL over the period of the isotope infusion. It also assumes that the major de novo fatty acid is 16:0, with minor elongation and/or desaturation to palmitoleate (16:1), stearate (18:0), and oleate (9c-18:1). De novo synthesis of 18:0 can be measured by MIDA (8), but 16:1 and $9 \mathrm{c}-18: 1$ are not easily measured by similar GCMS for technical reasons (fragmentation of the double bond, generating nonmolecular ions). Finally, the infused isotopic acetate must have no physiologically important effect. In this study, the fractional synthesis of 16:0 is considered to reflect absolute rates of 16:0 synthesis.

Sodium $\left[1-{ }^{13} \mathrm{C}\right]$ acetate (ISOTEC, Miamisburg, $\left.\mathrm{OH}\right)(>99 \%$ pure and $>98 \%$ enriched) in 1 liter of $1 / 2$ normal saline or sterile water was infused by vein at a rate of $370 \mathrm{mg} / \mathrm{h}$ beginning $7-16 \mathrm{~h}$ before the first meal and continuing for a total of 15-24 h. Subjects 1 and 8 were infused for $7 \mathrm{~h}$ before the first meal for a total of $15 \mathrm{~h}$ until $1 \mathrm{~h}$ after the last meal, according to standard protocol (8). Subjects 2 and 4 were infused for $9 \mathrm{~h}$ before the first meal for a total of $24 \mathrm{~h} \mathrm{(12:00} \mathrm{a.m.}$ to $12: 00$ a.m.). In subjects 1 and 4 on low fat diet A, there was a $17 \%$ increase in percent de novo VLDL TG 16:0 from 8:00 a.m. to 9:00 a.m. before the first meal. For this reason, in all subsequent studies, the duration of the acetate infusion before the first meal was increased to $15 \mathrm{~h}$ to ensure a plateau in ${ }^{13} \mathrm{C}$ enrichment of $16: 0$ before meals. The infusion was continued until $1 \mathrm{~h}$ after the last meal for a total of $24 \mathrm{~h}$ (6:00 p.m. to 6:00 p.m.). Two to three samples taken 2-4 h apart confirmed a steady state ${ }^{13} \mathrm{C}$ enrichment in $16: 0$ before meals by 12-15 $\mathrm{h}$ of ${ }^{13} \mathrm{C}$-acetate infusion for low fat diet $\mathrm{A}$ and by $7 \mathrm{~h}$ of acetate infusion for the high fat diet $\mathrm{B}$. In all subjects, the calculated ${ }^{13} \mathrm{C}$ enrichment in the acetyl CoA precursor pool (p) plateaued at 5-10\% within $7 \mathrm{~h}$ of the start of the infusion and was similar during the day. 
Isolation of $V L D L$. Every 2-3 d, at least $12 \mathrm{~h}$ after the last meal, $15 \mathrm{ml}$ of blood was sampled, put in EDTA on ice, and the plasma was separated by low speed centrifugation at $4^{\circ} \mathrm{C}$ for $20 \mathrm{~min}$ within $1 \mathrm{~h}$ of blood sampling. After adding inhibitors of lipases and proteases (phenylmethylsulfonyl chloride, leupeptin, and pepstatin), VLDL was isolated by density gradient separation using a TH-641 (Sorvall Instruments, Newton, CT) or SW41 swinging bucket rotor (Beckman Instruments, Inc., Fullerton, CA) (18). $2 \mathrm{ml}$ of plasma was carefully overlaid with $11 \mathrm{ml}$ of saline containing $1 \mathrm{mg} / \mathrm{ml}$ EDTA and spun at $20^{\circ} \mathrm{C}$ and $37,000 \mathrm{rpm}$ for $18 \mathrm{~h}$. In the samples obtained over $15-24 \mathrm{~h}$ during the ${ }^{13} \mathrm{C}$-acetate studies, the chylomicrons were first separated by a 40 -min spin at $20^{\circ} \mathrm{C}$ and $28,000 \mathrm{rpm}$, removed in the top $2.5 \mathrm{ml}$ of saline, the saline replaced, and the VLDL isolated with the 18-h spin. In a subset of samples, SDS-PAGE and laser densitometry were used to estimate the relative proportions of apolipoprotein B48 and B100 in VLDL and to confirm the exclusion of chylomicrons.

Lipid extraction and fatty acid analysis. The lipid was extracted from VLDL with Folch solvent (chloroform/methanol 2:1) (19) after the addition of C17:0 TG, cholesterol ester, and phospholipid internal standards to correct for procedural losses (Nu Chek Prep, Inc., Elysian, MN and Sigma Immunochemicals, St. Louis, MO). The total plasma lipid was also immediately extracted with Folch solvent from $1 \mathrm{ml}$ of the plasma prepared as described above, after the addition of C17:0 TG and C17:0 free fatty acid. The lipid fractions were separated by thin layer chromatography using silica gel $\mathrm{G}$ plates and a solvent system of hexane/diethyl ether/glacial acetic acid, 60:40:1. The plate was sprayed with rhodamine $\mathrm{G}$ and visualized with ultraviolet light, and the bands of interest were scraped into tubes containing $2 \mathrm{ml}$ of $5 \%$ methanolic $\mathrm{HCl}$. The tubes were capped with nitrogen, heated at $70^{\circ} \mathrm{C}$ for $2 \mathrm{~h}$, cooled, and the fatty acid methyl esters were extracted with hexane after the addition of water.

The fatty acid compositions of adipose tissue and formula diets were similarly analyzed after Folch extraction and transmethylation of the total lipid extract ( $>98 \%$ TG). Subcutaneous adipose tissue from the abdominal and gluteal regions was aspirated through a needle attached to a syringe after local anesthesia with $1 \%$ lidocaine within 3 wk of admission and at the end of each diet (20).

A gas chromatograph (model 5890; Hewlett-Packard Co., Palo Alto, CA) equipped with a flame ionization detector and a $100 \mathrm{~m} \times$ $0.25 \mathrm{~mm}(0.2-\mu \mathrm{m}$ coating) SP2560 fused silica capillary column (Supelco Inc., Bellefonte, PA) was temperature-programmed as described previously, with slight modifications (21). 43 peaks were identified from 10:0 and 22:6n-3, and the percent area (weight percentage) was obtained for each fatty acid at a detection limit of at least $0.1 \%$. Quantitative fatty acid methyl ester standards (Nu Chek Prep, Inc.) were run monthly and indicated that no area response correction factors were required.

GCMS. The fatty acid methyl esters prepared from samples obtained during the ${ }^{13} \mathrm{C}$-acetate studies were shipped overnight in dry ice to the University of California at Berkeley. A GC/MS (model 5970; Hewlett-Packard Co.) with a $15-\mathrm{m}$ DB1 column held at $200^{\circ}$ was used to quantitate the molecular ions of methyl 16:0 (m/z 270274) using electron-impact ionization and selected ion monitoring mode (8). Excess enrichment was calculated by subtraction of true baseline (unenriched) samples from each subject. The alogarithms for calculation of $(\mathrm{p}),(\mathrm{A} 1 *)$, and (f) have been described in detail previously (9).

Analysis of cholesterol, TG, $H D L-C$, glucose, and insulin. The total plasma cholesterol and TG were measured enzymatically (reagents from Boehringer Mannheim Corp., Indianapolis, IN) and the HDL-C was measured after precipitation of apo B containing lipoproteins by dextran sulfate (22). Glucose was measured by glucose oxidase or hexokinase assays. Insulin was analyzed in duplicate by radioimmunoassay (23).

Indirect calorimetry. The resting energy expenditure (REE) and respiratory quotient (RQ) were calculated from the analysis of breath samples using an MMC Horizon metabolic cart (Beckman Instruments, Inc.) or a DeltaTrac metabolic cart (Sensormedic, Yorba
Linda, CA) with a ventilated hood. On day 0 and every 4-5 d, measurements of $\mathrm{CO}_{2}$ production and $\mathrm{O}_{2}$ consumption were made every $30-60 \mathrm{~s}$ for $30 \mathrm{~min}$ in the morning, $12 \mathrm{~h}$ after the last meal, and after at least $20 \mathrm{~min}$ of rest. In addition, on the day of the ${ }^{13} \mathrm{C}$-acetate study, gas exchange was measured after $20 \mathrm{~min}$ of rest and beginning $30 \mathrm{~min}$ after the start of the last meal for $30 \mathrm{~min}$. On that day, meals were consumed every $2 \mathrm{~h}$ and were completed within $30 \mathrm{~min}$. For each 30 -min measurement, the mean of values obtained during the second $15 \mathrm{~min}$ was used for comparative analysis.

The RQs were corrected for protein oxidation that was estimated from the difference between nitrogen intake and nitrogen excretion (in urinary urea, creatinine, and uric acid) in urine produced at the time of calorimetry or from 24-h urine collections the same day. Since nitrogen excretions were similar by both calculations, only RQs corrected with the 24-h urine collections are presented.

Statistical methods. Simple regression analysis was used to confirm a steady state in VLDL TG fatty acids and weight in the last $2 \mathrm{wk}$ of the dietary period. A steady state in VLDL TG \%18:2 was defined as a variation about the mean of $<20 \%$ and a slope not significantly different from zero. For each subject on each diet, the differences between the steady state values for the \%18:2 in VLDL TG and the $\% 18: 2$ in the diet and adipose tissue were calculated, and the withinsubject difference in each diet group was statistically analyzed by paired $t$ test. The differences were also used to calculate the mean steady state percent de novo VLDL TG for each subject and the mean for each diet group. Differences in percent de novo VLDL TG between diet groups were statistically analyzed by two-tailed unpaired $t$ test that assumed unequal variance. The mean of values obtained in the last week of the diet (fasting insulin, glucose, TG, lipoprotein cholesterol) or the last 2 wk (fasting resting metabolic rate and RQ) were compared to prediet values by paired $t$ test or between diet groups by unpaired $t$ test. Relationships between continuous variables such as percent de novo VLDL TG and insulin were evaluated with simple linear regression analysis. Data analysis was performed using Excel statistical software.

\section{Results}

Adipose tissue and diet fatty acid compositions. As predicted, there was only minimal change in the fatty acid composition of adipose tissue after either diet. Table III shows the mean percentages of the major fatty acids: $18: 2,16: 0$, and 9c-18:1, and selected minor fatty acids in the adipose tissues before and after low fat diet A and high fat diet B (AT pre-diet and AT postdiet). The value from each subject is the average of values from the abdominal and gluteal sites. For each subject, the difference between sites was small. There was slightly higher 16:0 (mean 20.8 vs. $18.3 \%$ ) and lower 9c-18:1 (mean 38.4 vs. $40.7 \%$ ) in abdominal versus gluteal adipose tissue, with minimal difference in $18: 2$ (mean 16.5 vs. $16.3 \%$ ) or other polyunsaturates, as reported previously $(24,25)$.

Table III also shows that the fatty acid compositions of the diets $(D I E T)$ were closely matched to the compositions of the adipose tissue for the major and most of the minor fatty acids. 18:0 was higher and 16:1 lower in the diet than in the adipose tissue, but these fatty acids formed a small percentage of the total.

Percent de novo VLDL TG by the linoleate dilution method. The average of the diet and adipose tissue concentration of 18:2 at the end of the diet $(D I E T-A T)$ is given next in Table III. This should be compared with the mean concentration of 18:2 in VLDL TG in the last 2 wk of study (VLDL). The difference between the 18:2 of VLDL TG and the dietadipose tissue is expressed as the percent difference: (VLDL DIET-AT) $\times 100 /$ DIET-AT. The values for the two other ma- 


\begin{tabular}{|c|c|c|c|c|c|c|c|c|c|c|c|}
\hline & \multicolumn{3}{|c|}{ Major fatty acids (wt $\%$ ) } & \multicolumn{8}{|c|}{ Minor fatty acids (wt $\%$ ) } \\
\hline & $18: 2$ & $16: 0$ & $9 c-18: 1$ & 14:0 & $9 \mathrm{c}-16: 1$ & 18:0 & $11 \mathrm{c}-18: 1$ & $\operatorname{tr}-18: 1$ & $18: 3 n-3$ & $20: 4 n-6$ & $22: 6 n-3$ \\
\hline \multicolumn{12}{|l|}{ Low fat diet A (subjects 1-7) } \\
\hline AT pre-diet* & 15.39 & 19.55 & 39.71 & 2.90 & 5.51 & 4.13 & 2.48 & 2.63 & 0.54 & 0.34 & 0.11 \\
\hline AT post-diet ${ }^{\ddagger}$ & 14.65 & 19.72 & 39.82 & 2.68 & 5.86 & 3.97 & 2.80 & 2.65 & 0.64 & 0.42 & 0.12 \\
\hline DIET $^{\S}$ & 14.91 & 19.07 & 39.69 & 1.28 & 1.43 & 12.00 & 2.62 & 3.23 & 0.46 & 0.07 & 0.00 \\
\hline $\begin{array}{l}\text { DIET-AT" } \\
\text { (range) }\end{array}$ & $\begin{array}{c}14.78 \\
(10-19)\end{array}$ & $\begin{array}{c}19.40 \\
(18-20)\end{array}$ & $\begin{array}{c}39.76 \\
(37-42)\end{array}$ & 1.98 & 3.65 & 7.99 & 2.71 & 2.94 & 0.55 & 0.24 & 0.06 \\
\hline $\begin{array}{l}\text { VLDL }^{\mathscr{I}} \\
\text { (range) }\end{array}$ & $\begin{array}{c}8.27 \\
(5-11)\end{array}$ & $\begin{array}{c}29.85 \\
(28-34)\end{array}$ & $\begin{array}{c}34.36 \\
(32-39)\end{array}$ & 2.74 & 6.94 & 4.15 & 3.68 & 1.24 & 0.25 & 1.25 & 0.38 \\
\hline Percent difference ${ }^{* *}$ & -43.65 & 54.08 & -13.62 & & & & & & & & \\
\hline $\begin{array}{l}\text { SD } \\
\text { (range) }\end{array}$ & $\begin{array}{c}10.40 \\
(-30 \text { to }-57)\end{array}$ & $\begin{array}{c}11.80 \\
(41-79)\end{array}$ & $\begin{array}{c}3.32 \\
(-7 \text { to }-16)\end{array}$ & & & & & & & & \\
\hline Percent de novo VLDL TG & 43.65 & & & & & & & & & & \\
\hline \multicolumn{12}{|l|}{ High fat diet B (subjects 8-10) } \\
\hline AT pre-diet* & 18.76 & 18.02 & 39.15 & 2.11 & 4.65 & 3.52 & 2.40 & 2.72 & 0.58 & 0.40 & 0.06 \\
\hline AT post-diet ${ }^{\ddagger}$ & 18.19 & 18.22 & 38.61 & 2.11 & 4.29 & 3.84 & 2.40 & 2.81 & 0.51 & 0.44 & 0.13 \\
\hline DIET $^{\S}$ & 18.41 & 17.99 & 40.36 & 0.90 & 1.31 & 10.77 & 2.80 & 3.10 & 0.50 & 0.07 & 0.00 \\
\hline $\begin{array}{l}\text { DIET-AT" } \\
\text { (range) }\end{array}$ & $\begin{array}{c}18.30 \\
(16-23)\end{array}$ & $\begin{array}{c}18.11 \\
(17-19)\end{array}$ & $\begin{array}{c}39.49 \\
(37-41)\end{array}$ & 1.50 & 2.80 & 7.31 & 2.60 & 2.96 & 0.51 & 0.26 & 0.07 \\
\hline $\begin{array}{l}\text { VLDL }^{q} \\
\text { (range) }\end{array}$ & $\begin{array}{c}19.59 \\
(17-24)\end{array}$ & $\begin{array}{c}20.82 \\
(20-21)\end{array}$ & $\begin{array}{c}36.10 \\
(33-38)\end{array}$ & 1.34 & 2.26 & 4.48 & 3.17 & 1.88 & 0.28 & 1.37 & 0.36 \\
\hline Percent difference** & 7.09 & 15.11 & -8.62 & & & & & & & & \\
\hline $\begin{array}{l}\mathrm{SD} \\
\text { (range) }\end{array}$ & $\begin{array}{r}1.17 \\
(6-8)\end{array}$ & $\begin{array}{c}4.03 \\
(11-19)\end{array}$ & $\begin{array}{c}2.33 \\
(-6 \text { to }-10)\end{array}$ & & & & & & & & \\
\hline Percent de novo VLDL TG & 0.00 & & & & & & & & & & \\
\hline
\end{tabular}

*AT pre-diet, mean of each of 11 fatty acids (wt \%) in adipose tissues before diets A or B; ${ }^{\ddagger}$ AT post-diet, mean of each of 11 fatty acids (wt $\%$ ) in adipose tissues after diets A or B; ${ }^{\circledR}$ DIET, mean fatty acid composition of diets A or B; ${ }^{D}$ DIET-AT, mean of AT (post-diet) and diets A or B; ${ }^{q}$ VLDL, mean fatty acid composition of VLDL TG sampled the last 2 wk of diets A or B; **Percent difference, (VLDL - DIET-AT) $\times 100 /$ DIET-AT; \#Percent de novo VLDL TG $=\%$ difference, or \% decrease, in 18:2 in VLDL TG vs. DIET-AT.

jor fatty acids, 16:0 and 9c-18:1, are also given. Finally, the percent de novo VLDL TG is listed which is equal to the percent difference in 18:2 when the value is negative or to zero when the value is zero or positive.

On low fat diet A, in all subjects, the fatty acid composition of VLDL TG was dramatically different from the compositions of the diet and adipose tissue. The mean VLDL TG \%18:2 was $44 \%$ lower and the mean $16: 0$ was $54 \%$ higher than values in the diet and adipose tissue. In sharp contrast, on high fat diet $\mathrm{B}$, the \%18:2 and \%16:0 in VLDL TG were similar to the concentrations in the diet and adipose tissue. Thus, as calculated by our model, a substantial fraction (30-57\%) of VLDL TG was formed de novo on low fat diet A, but very little was formed de novo on high fat diet B.

In Fig. 2, the time courses of the changes in the mean difference between VLDL TG and diet-adipose tissue for 18:2 and 16:0 are illustrated in the top and bottom panels, respectively. On low fat diet A, the \%18:2 in VLDL TG sharply fell from baseline levels that reflected the diet in the few days preceding hospital admission. It stabilized far below the concentration in the diet and adipose tissue in 7-10 d. The average within-subject and between-subject coefficients of variation for days 11-25 were low (21 and 24\%, respectively), and the slopes of regression lines for this period were all insignificantly different from zero. As the \%18:2 decreased, the \%16:0 increased and stabilized at a concentration that was much higher than the concentration in the diet and adipose tissue. In contrast, on high fat diet B, there was less change in both fatty acids from baseline and a faster equilibration to concentrations that were similar to the concentrations in the diet and adipose tissue.

Fig. 3 shows that the distinct fatty acid pattern for each diet persisted over $24 \mathrm{~h}$ and did not fluctuate with meals. Since the plasma half-life of VLDL TG is typically no more than 2-3 h, this suggests that the dietary effects on fatty acid synthesis were prolonged or that VLDL TG half-life was increased due to delayed clearance or to an increase in the extraplasma TG pool size.

Although the numbers of subjects are small, males and females had similar responses to low fat diet A (50 vs. 39\% de novo VLDL TG, respectively). In each of the three females, based on the date of the start of menses, the 2-wk steady state in plasma fatty acid composition spanned both follicular and luteal phases. In this short time frame, there was no evidence 


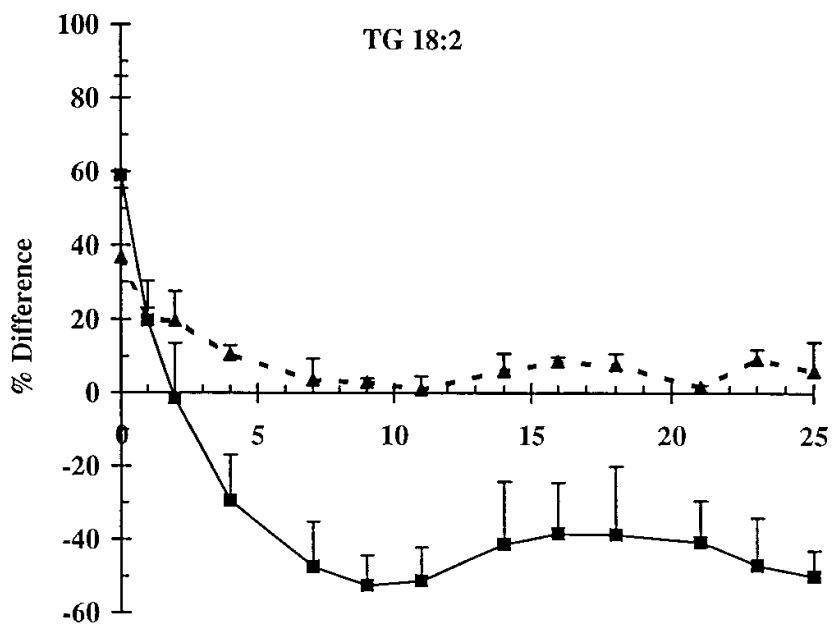

TG 16:0

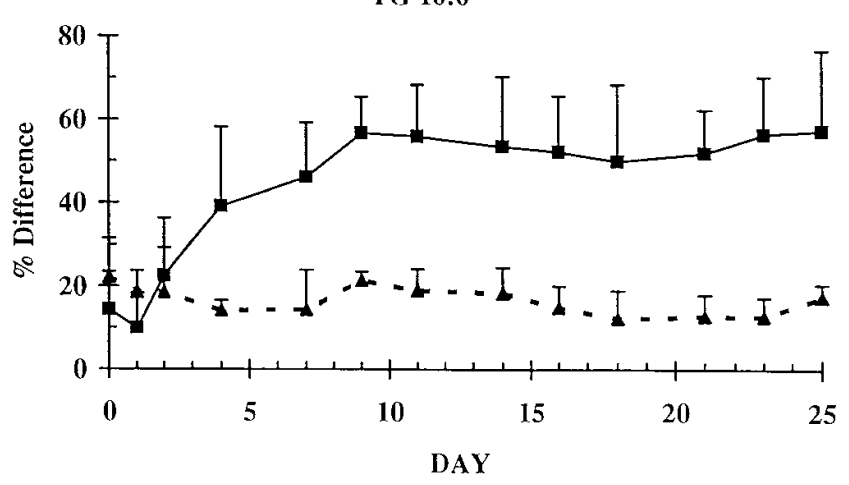

Figure 2. Percent differences (mean \pm SD) between the fatty acid compositions of VLDL TG and the diet-adipose tissue during the $25 \mathrm{~d}$ of study for low fat diet A (squares, $n=7$ ) and high fat diet B (triangles, $n=3$ ). Top, TG 18:2; bottom, TG 16:0. Percent difference $=$ (VLDL TG \%18:2 - diet-adipose tissue \%18:2) × 100/diet-adipose tissue \%18:2. Negative values for 18:2 are equal to the percent de novo VLDL TG by the linoleate dilution method.

for higher fatty acid synthesis during the follicular compared with luteal phases, as reported previously in a small number of free-living female subjects on ad libitum diets studied with ${ }^{13} \mathrm{C}$ acetate (11).

On both diets, 9c-18:1, the monounsaturated fatty acid comprising the largest percentage of the total fatty acids $(\sim 35 \%)$, was slightly lower in VLDL TG compared with the diet-adipose tissue. On the low fat diet A, two minor monounsaturated fatty acids that we cited previously as potential biomarkers of increased fatty acid synthesis, 16:1 and cis-vaccenate (11c-18:1), were slightly increased (6.9 vs. $3.7 \%$ and 3.7 vs. $2.7 \%$, respectively) (21). The significance of these increases is uncertain, since it was not possible to exactly match the concentration of 16:1 in the diet and adipose tissue, and the 11c18:1 was also increased in plasma relative to the diet and adipose tissue on high fat diet $\mathrm{B}$.

As expected, the plasma concentrations of minor fatty acids derived exclusively from the diet or adipose tissue, linolenate (18:3n-3) and trans 18:1, were lower relative to the diet and adipose tissue on low fat diet $\mathrm{A}$ than high fat diet B. Arachidonate (20:4n-6) and docosohexadecanoate (22:6n-3)
TG 18:2

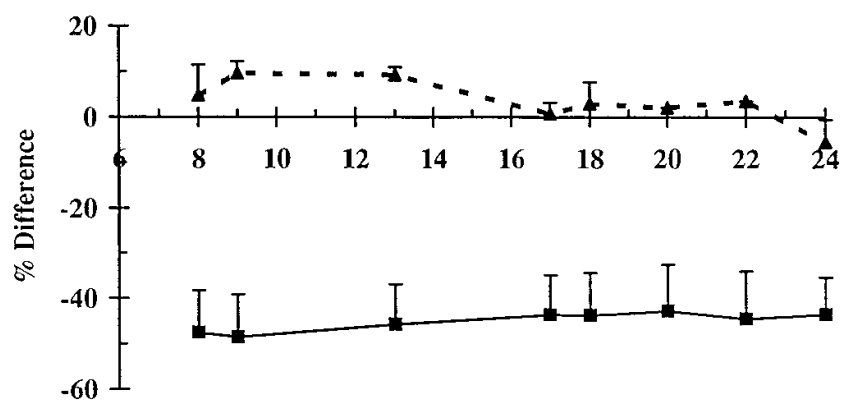

TG 16:0

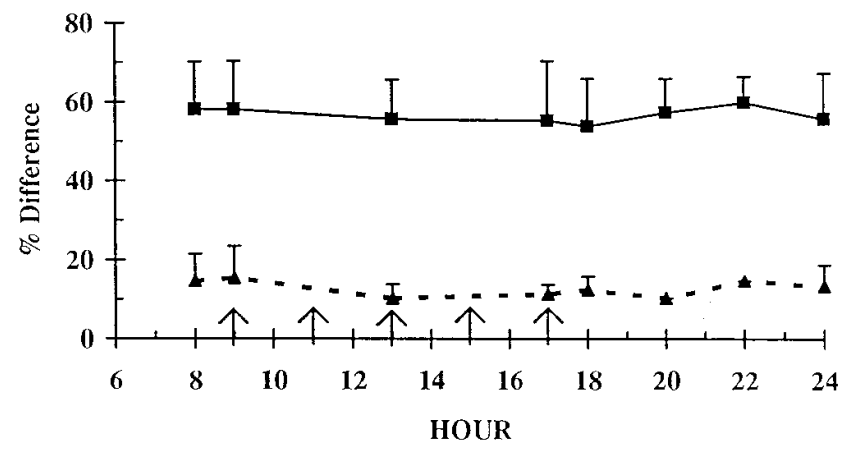

Figure 3. Percent differences (mean \pm SD) between the fatty acid compositions of VLDL TG and the diet-adipose tissue during the day at the end of low fat diet A (boxes, $n=7$ ) and high fat diet B (triangles, $n=3$ ). Top, TG 18:2; bottom, TG 16:0. Percent difference calculated as in Fig. 2 and text. The arrows mark the meal times.

were higher in VLDL TG compared with the diet-adipose tissue on both diets, possibly indicating increased synthesis from the precursors, 18:2 n-6 and 18:3 n-3, respectively, and/or slow plasma clearance. Differences in these minor fatty acids have minimal effects on the relative concentrations of 18:2,16:0, and 9c-18:1.

The fatty acid composition of TG isolated from the total plasma lipid extract was nearly identical to the composition of the VLDL TG at all time points. In addition, large decreases in the $\% 18: 2$ occurred with a similar time course in the free fatty acids, as well as in the cholesterol ester and phospholipid fractions of VLDL (data not shown). Thus, there was no evidence for accumulation of 18:2 in other lipid classes or in TG carried by LDL or HDL.

Percent de novo VLDL TG 16:0 by the isotopic method $(M I D A)$. The results with the MIDA method after intravenous infusions of ${ }^{13} \mathrm{C}$-acetate were qualitatively similar to the results based on linoleate dilution. Fig. 4 shows that the mean percent de novo VLDL TG 16:0 was much higher on the low fat diet $\mathrm{A}$ than on the high fat diet after an overnight fast and throughout the day. The mean morning values after an overnight fast were $20 \pm 5 \%$ vs. $4 \pm 1 \%$, respectively, $P=0.0003$. The mean values $1 \mathrm{~h}$ after the last meal were $24 \pm 6 \%$ vs. $8 \pm 3 \%, P=0.0007$. On both diets, there was a slight, gradual increase during the day that was not seen in the fatty acid composition (Fig. 3). Table IV shows the individual data used to 


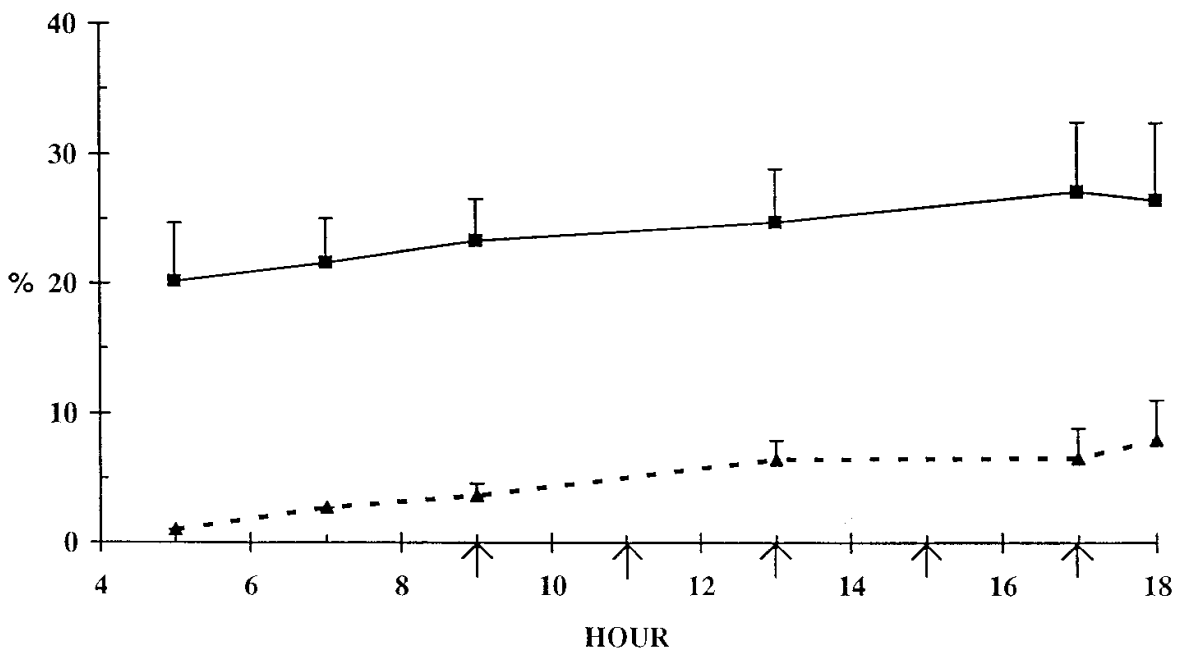

Figure 4. Percent de novo VLDL TG 16:0 (mean \pm SD) by the isotopic MIDA method. ${ }^{13} \mathrm{C}$-Acetate was infused intravenously for $15-24 \mathrm{~h}$, and the incorporation into plasma VLDL TG 16:0 was measured during the day at the end of low fat $\operatorname{diet} \mathrm{A}$ (squares, $n=7$ ) and high fat diet $\mathrm{B}$ (triangles, $n=3)$. Arrows indicate meal times. calculate fractional 16:0 synthesis (f) before the first meal (Fasted) and $1 \mathrm{~h}$ after the last meal (Fed).

Plasma TG concentrations. To determine the relationship between fatty acid synthesis and plasma TG concentration, the plasma TG concentration was monitored during the $25 \mathrm{~d}$ of study and over $24 \mathrm{~h}$ at the end of each study. Table $\mathrm{V}$ first shows the mean values obtained after an overnight fast on day 0 ; these were similar to the means of two to three samples obtained after ad libitum diets (see Table I). On low fat diet A, the plasma TG tripled to a peak at 4-10 d, within a few days of the onset of constant VLDL fatty acid composition (mean 2.87 vs. $0.89 \mathrm{mM}, P=0.003$ ). In all but subject 3 who maintained the peak value, the TG concentrations then declined and leveled off by the last week (mean of days 21, 23, and 25) at twice the level on day 0 (1.85 vs. $0.89 \mathrm{mM}, P=0.007)$. In parallel with the increase in total TG, there was an increase in VLDL TG (data not shown). Samples obtained over $24 \mathrm{~h}$ at the end of the diet showed that the TG concentration further increased in some, but not all, subjects until after the last meal, when it declined until the morning.

On high fat diet B, the TG concentration after an overnight fast also increased by day 10 from day 0 values (1.62 vs. 1.13 $\mathrm{mM}, P=0.15)$. However, the mean fasting TG concentrations (and VLDL TG) in the last week were similar to baseline values $(1.19$ vs. $1.13, P=0.86)$. These values were also less than mean values obtained in the last week after the low fat diet A, but with the small number of subjects, the difference between diets was not statistically significant ( 1.19 vs. $1.85 \mathrm{mM}, P=0.33)$. For both diets, the average area under the curve was plotted over $24 \mathrm{~h}$ from five TG values obtained just before the first meal (9:00 a.m.), just before the third meal (1:00 p.m.), and 1 and $4 \mathrm{~h}$ after the last meal (6:00 p.m. and 10:00 p.m.). The 24-h area for TG was lower for high fat diet B than for low fat diet A, but the difference was not statistically significant (32.15 vs. $41.83 \mathrm{mM} / 24 \mathrm{~h}, P=0.53)$.

On low fat diet A, when the increase in total plasma TG on day 25 above day 0 values was expressed as a percentage of the day 25 value, the percentage was similar to percent de novo VLDL TG calculated by the linoleate dilution method (Table III, Low fat diet $A$ ): mean $47 \pm 12 \%$ vs. $43 \pm 10 \%$. This supported the possibility that the diet-induced increase in plasma TG was primarily due to increased fatty acid synthesis. How- ever, subjects 4 and 7 had TG increases that were greater than predicted by decreases in VLDL TG \%18:2, and regression analysis indicated no statistically significant relationship between TG or increase in TG above baseline and percent de novo VLDL TG. Furthermore, all but one subject had a peak and then decline in the fasting TG between days 10 and 18 when there was no change in the \%18:2. Thus, it was likely that the TG concentration was increased not only by increased fatty acid synthesis, but also by other factors, such as increased TG synthesis from preformed fatty acids or decreased TG clearance. Delayed clearance of chylomicrons did not significantly contribute to the peak elevation in plasma TG on low fat diet A, since apolipoprotein B48, a marker of chylomicrons, was $<5 \%$ of the total apolipoprotein B $(\mathrm{B} 100+\mathrm{B} 48)$ in samples from subjects 4-6.

Insulin and glucose concentrations. To determine if increases in insulin and/or glucose paralleled the increases in fatty acid synthesis and TG concentrations, blood insulin and glucose concentrations were also monitored at the same time intervals described above for blood TG. Table V shows that, on both diets, serum insulin and glucose levels obtained after an overnight fast in the last week (day 25) were similar to values on day 0 and did not differ between diets. On low fat diet A, insulin levels were markedly increased from fasting values $1 \mathrm{~h}$ after the start of the last meal (174 vs. $6 \mu \mathrm{U} / \mathrm{ml})$; in contrast, glucose values were only slightly increased without evidence for glucose intolerance in any subject (6.17 vs. $4.61 \mathrm{mM})$. Regression analysis indicated no significant linear relationship between the insulin or glucose responses and the percent de novo VLDL TG, TG, or increase in TG in subjects on low fat diet A $(P>0.01)$.

On high fat diet B, insulin levels were less increased $1 \mathrm{~h}$ after the last meal, but the difference between diets was not statistically significant ( 83 vs. $174 \mu \mathrm{U} / \mathrm{ml}, P=0.20$ ). On both diets, insulin and glucose levels returned nearly to baseline values by 10:00 p.m., $5 \mathrm{~h}$ after the last meal.

Cholesterol concentrations. The increase in the plasma TG in the last week of low fat diet A was associated with a consistent and significant decrease in the mean total plasma cholesterol and HDL-C from ad libitum values (3.38 vs. $4.10 \mathrm{mM}$, $P=0.01$ and 0.79 vs. $1.21 \mathrm{mM}, P=0.01$, respectively). The relationship between HDL-C and TG was not reciprocal, how- 


\begin{tabular}{|c|c|c|c|c|c|c|}
\hline Subject & EM1 & EM2 & EM2/EM1 & $\mathrm{p}$ & $\mathrm{A} 1 *$ & $\mathrm{f}$ \\
\hline & & & & $M P E$ & $M P E$ & $\%$ \\
\hline \multicolumn{7}{|l|}{ Low fat diet $\mathrm{A}$} \\
\hline 1. Fasted & 0.0212 & 0.0092 & 0.4330 & 0.0486 & 0.1822 & 11.63 \\
\hline Fed & 0.0356 & 0.0150 & 0.4239 & 0.0469 & 0.1780 & 19.93 \\
\hline 2. Fasted & 0.0370 & 0.0248 & 0.6711 & 0.0906 & 0.2483 & 14.90 \\
\hline Fed & 0.0441 & 0.0303 & 0.6872 & 0.0932 & 0.2506 & 17.59 \\
\hline 3. Fasted & 0.0476 & 0.0207 & 0.4360 & 0.0492 & 0.1835 & 25.85 \\
\hline Fed & 0.0606 & 0.0262 & 0.4329 & 0.0486 & 0.1821 & 33.16 \\
\hline 4. Fasted & 0.0449 & 0.0302 & 0.6722 & 0.0908 & 0.2484 & 18.07 \\
\hline Fed & 0.0525 & 0.0328 & 0.6245 & 0.0829 & 0.2403 & 21.83 \\
\hline 5. Fasted & 0.0436 & 0.0218 & 0.5010 & 0.0613 & 0.2088 & 20.91 \\
\hline Fed & 0.0507 & 0.0279 & 0.5509 & 0.0703 & 0.2237 & 22.73 \\
\hline 6. Fasted & 0.0398 & 0.0188 & 0.4720 & 0.0560 & 0.1984 & 20.06 \\
\hline Fed & 0.0429 & 0.0220 & 0.5132 & 0.0635 & 0.2128 & 20.22 \\
\hline 7. Fasted & 0.0558 & 0.0286 & 0.5129 & 0.0635 & 0.2167 & 26.22 \\
\hline Fed & 0.0654 & 0.0357 & 0.5465 & 0.0695 & 0.2225 & 29.37 \\
\hline Mean fasted & 0.0414 & 0.0220 & 0.5283 & 0.0657 & 0.2123 & 19.66 \\
\hline $\mathrm{SD}$ & 0.0107 & 0.0070 & 0.1023 & 0.0179 & 0.0276 & 5.37 \\
\hline Mean fed & 0.0503 & 0.0271 & 0.5399 & 0.0678 & 0.2157 & 23.55 \\
\hline SD & 0.0104 & 0.0070 & 0.0954 & 0.0169 & 0.0274 & 5.62 \\
\hline \multicolumn{7}{|l|}{ High fat diet B } \\
\hline 8. Fasted & 0.0073 & 0.0045 & 0.6108 & 0.0806 & 0.2376 & 3.09 \\
\hline Fed & 0.0207 & 0.0110 & 0.5316 & 0.0668 & 0.2183 & 9.48 \\
\hline 9. Fasted & 0.0084 & 0.0089 & 1.0672 & 0.1474 & 0.2840 & 3.11 \\
\hline Fed & 0.0118 & 0.0114 & 0.9687 & 0.1346 & 0.2766 & 4.38 \\
\hline 10. Fasted & 0.0121 & 0.0090 & 0.7419 & 0.1018 & 0.2576 & 4.70 \\
\hline Fed & 0.0241 & 0.0157 & 0.6531 & 0.0876 & 0.2454 & 9.81 \\
\hline Mean fasted & 0.0093 & 0.0075 & 0.8066 & 0.1099 & 0.2597 & 3.63 \\
\hline SD & 0.0025 & 0.0026 & 0.2350 & 0.0341 & 0.0233 & 0.92 \\
\hline Mean fed & 0.0189 & 0.0127 & 0.7178 & 0.0963 & 0.2468 & 7.89 \\
\hline SD & 0.0064 & 0.0026 & 0.2256 & 0.0347 & 0.0292 & 3.04 \\
\hline
\end{tabular}

Infusions of ${ }^{13} \mathrm{C}$-acetate and analysis of plasma VLDL TG by GCMS were performed as described in the text. $p$, isotopic enrichment of acetate precursor; $A 1^{*}$, asymptotic enrichment of M1 isotopomer if $100 \%$ of $16: 0$ were synthesized from acetyl-CoA units at enrichment p; $f$, fraction of $16: 0$ derived from endogenous synthesis; $M P E$, molar percent excess. Fasted $=12 \mathrm{~h}$ of overnight fast just before first meal; Fed $=$ value $1 \mathrm{~h}$ after last of five meals given every $2 \mathrm{~h}$ for $8 \mathrm{~h}$.

ever, since, in all subjects, the HDL-C rapidly declined and then plateaued by day 5 , several days before the peak in TG. The decrease in HDL-C was disproportionately greater than the decrease in total cholesterol, so that the cholesterol/HDL-C increased from baseline values (mean of 4.35 vs. $3.51, P=$ 0.01 ). On the high fat diet $\mathrm{B}$, similar but much smaller changes from baseline occurred in total cholesterol (3.51 vs. $4.38 \mathrm{mM})$, HDL-C (0.90 vs. $1.26 \mathrm{mM}$ ), and cholesterol/HDL-C (4.0 vs. 3.7), which were not statistically significant. On both diets, there were minimal changes in total cholesterol and HDL-C over $24 \mathrm{~h}$.

Energy expenditure. On low fat diet A, the actual total calories required to maintain weight and the expected calories calculated from surface area were nearly identical $(2,386 \pm 398$ vs. $2,374 \pm 340, P=0.95)$. Consistent with these findings, the mean REE measured by indirect calorimetry after an overnight fast three to four times in the last 2 wk of each diet was unchanged from values obtained on day $0(1,467 \pm 272$ vs. $1,431 \pm 331, P=0.22)$. For high fat diet $\mathrm{B}$, there was a similar lack of difference between actual and expected total calories required to maintain constant weight $(2,517 \pm 382$ vs. $2,637 \pm 287$, $P=0.69)$ and in REE post-diet versus baseline (1,575 \pm 315 vs. $1,564 \pm 281, P=0.71)$. At the end of the diet period, the percent increase in energy expended shortly after the last meal relative to the morning fasted value was slightly higher after low fat diet $\mathrm{A}$ than after high fat diet $\mathrm{B}$, but the difference was not statistically different ( 45 vs. $30 \%, P=0.13$ ). Thus, the caloric expenditure was similar on the low fat and high fat diets.

As expected with a higher intake of carbohydrate during low fat diet A (food quotient of 0.93), the mean nonprotein RQ after an overnight fast was slightly higher in the last $2 \mathrm{wk}$ compared with day $0(0.94 \pm 0.08$ vs. $0.88 \pm 0.04, P=0.15)$. Consistent with the lack of weight gain, no values were $>1.0$, indicating negligible net lipogenesis and net fat deposition. That is, 
Table V. Plasma TG, Insulin, and Glucose Concentrations on Low Fat Versus High Fat Diet

\begin{tabular}{|c|c|c|c|c|c|c|c|c|c|c|c|c|}
\hline \multirow[b]{2}{*}{ Subject } & \multicolumn{4}{|c|}{ Triglyceride (mM) } & \multirow[b]{2}{*}{ Hours } & \multirow[b]{2}{*}{$\begin{array}{l}\text { Percent de novo } \\
\text { VLDL TG }\end{array}$} & \multicolumn{3}{|c|}{ Insulin $(\mu \mathrm{U} / \mathrm{ml})$} & \multicolumn{3}{|c|}{ Glucose $(\mathrm{mM})$} \\
\hline & Day 0 & Peak & Days 21-25 & $\begin{array}{l}\text { Day } 25 \\
\text { fasted* }\end{array}$ & & & Day 0 & $\begin{array}{l}\text { Day } 25 \\
\text { fasted* }\end{array}$ & $\mathrm{Fed}^{\|}$ & Day 0 & $\begin{array}{l}\text { Day } 25 \\
\text { fasted* }\end{array}$ & Fed" \\
\hline \multicolumn{13}{|c|}{ Low fat diet A } \\
\hline 1 & 0.90 & 3.14 & 2.26 & 1.98 & 50.15 & 57 & 12 & 3 & 466 & 5.11 & 4.17 & 6.39 \\
\hline 2 & 0.80 & 1.50 & 1.23 & 1.15 & 26.20 & 37 & 2 & 7 & 125 & 5.28 & 4.50 & 6.67 \\
\hline 3 & 1.00 & 1.84 & 1.49 & 1.66 & 36.02 & 51 & 4 & 7 & 87 & 5.11 & 4.39 & 6.89 \\
\hline 4 & 1.36 & 5.33 & 3.78 & 3.49 & 89.14 & 30 & 10 & 6 & 279 & 5.56 & 4.78 & 6.50 \\
\hline 5 & 0.49 & 2.03 & 1.20 & 1.22 & 27.33 & 54 & 3 & 5 & 88 & 4.78 & 5.11 & 5.72 \\
\hline 6 & 0.72 & 2.80 & 1.18 & 1.08 & 20.90 & 39 & 7 & 5 & 96 & 5.28 & 4.89 & 6.17 \\
\hline 7 & 0.93 & 3.49 & 1.84 & 1.86 & 43.03 & 36 & 8 & 11 & 79 & 4.56 & 4.61 & 4.67 \\
\hline Mean & 0.88 & 2.88 & 1.86 & 1.78 & 41.82 & 43 & 7 & 6 & 174 & 5.10 & 4.63 & 6.14 \\
\hline SD & 0.27 & 1.30 & 0.94 & 0.84 & 23.22 & 10 & 4 & 2 & 146 & 0.33 & 0.32 & 0.75 \\
\hline \multicolumn{13}{|c|}{ High fat diet B } \\
\hline 8 & 1.42 & 2.32 & 2.00 & 1.90 & 54.48 & 0 & 2 & 6 & 147 & 4.94 & 5.06 & 7.28 \\
\hline 9 & 0.97 & 1.10 & 1.23 & 0.78 & 22.20 & 0 & 10 & 17 & 66 & 5.67 & 5.28 & 7.06 \\
\hline 10 & 0.98 & 1.47 & 0.35 & 0.70 & 19.77 & 0 & 20 & 25 & 37 & 4.78 & 4.72 & 3.89 \\
\hline Mean & 1.12 & 1.63 & 1.19 & 1.13 & 32.15 & $\mathbf{0}$ & 11 & 16 & 83 & 5.13 & 5.02 & 6.07 \\
\hline SD & 0.26 & 0.62 & 0.82 & 0.67 & 19.37 & 0 & 9 & 9 & 57 & 0.47 & 0.28 & 1.90 \\
\hline
\end{tabular}

*At 9:00 a.m., at least $12 \mathrm{~h}$ from the last meal; ${ }^{\ddagger}$ Calculated from area under the curve of TG concentrations over $24 \mathrm{~h}(\mathrm{mM} / 24 \mathrm{~h}) ;{ }^{\S} \mathrm{Calculated}$ from percent decrease in VLDL TG 18:2 below levels in the diet and adipose tissue (Table III); ${ }^{\| 1} \mathrm{~h}$ after the start of the last meal; five meals given every $2 \mathrm{~h}$ between 9:00 a.m. and 5:00 p.m.; Differences between day 0 and day 25, fasted, are statistically significant $(P<0.01)$ for TG on diet A only. All differences between low fat and high fat diets are statistically insignificant $(P>0.01)$ except percent de novo VLDL TG.

after an overnight fast, an equal amount of the fat that was synthesized was oxidized. On day 25 of low fat diet A, the mean nonprotein RQ $1 \mathrm{~h}$ after the last meal increased from that day's overnight fasted value by $9 \%$ to $1.06 \pm 0.13(P=$ $0.02)$, indicating slight net lipogenesis of unknown duration. On high fat diet B (food quotient 0.87 ), the mean nonprotein RQ after an overnight fast was also slightly increased from day 0 values $(0.92 \pm 0.06$ vs. $0.87 \pm 0.06, P=0.45)$. Compared with the low fat diet, there was a slightly smaller percent increase after the last meal relative to the morning fasted value (5 vs. $9 \%, P=0.69$ ), with no subject increasing above 1.0 .

\section{Discussion}

Net lipogenesis from carbohydrate has been previously demonstrated to occur in humans during positive calorie balance. It has been widely assumed that fatty acid synthesis does not occur during calorie balance. These studies were conducted in normal volunteers who were in calorie balance as indicated by the meticulous maintenance of stable body weight. They clearly demonstrate that fatty acid synthesis was stimulated even in the eucaloric state by very low fat, high carbohydrate diets in all subjects.

By matching the fatty acid compositions of the diet and adipose tissue and monitoring the percent decrease in 18:2 in VLDL TG below the concentration in the diet and adipose tissue by de novo fatty acids, we calculated that about half of the VLDL TG fatty acids were newly formed. The large decreases in 18:2 were associated with large increases in 16:0 in VLDL TG that stabilized within $10 \mathrm{~d}$ of the dietary intervention and persisted over $24 \mathrm{~h}$. In contrast, on the high fat diet, the fatty acid composition of VLDL TG was similar to the composition of the diet and adipose tissue, as expected in the absence of de novo fatty acids or other selectivity in fatty acid metabolism. Isotopic studies using ${ }^{13} \mathrm{C}$-acetate with the MIDA technique directly demonstrated that the increase in 16:0 on the low fat diet was associated with increased de novo 16:0 synthesis. These results suggest that this new method is a valid way to simultaneously study over time the effect of an intervention on the fatty acid synthesis and the fatty acid composition of plasma lipid subfractions.

In a small number of previous studies, similar increases in 16:0 and decreases in 18:2 in plasma provided indirect evidence that significant fatty acid synthesis occurred in humans on low fat, high carbohydrate diets. A Rockefeller study many years ago showed large increases in plasma TG and VLDL TG, a doubling of the \%16:0, and a sixfold reduction in $\% 18: 2$ in TG-rich lipoproteins relative to levels in adipose tissue in two severely hypertriglyceridemic men fed eucaloric fat-free formula diets for $7 \mathrm{~d}$ (26). This fatty acid response was confirmed in eight other male and female hypertriglyceridemic subjects fed fat-free diets for 2-3 wk (27). A similar fatty acid pattern was induced in the plasma TG of normal volunteers by 2-wk, continuous fat-free intravenous or nasogastric infusions (28). In addition, we reported that the adipose tissue of weightstable subjects receiving long-term home intravenous nutrition varying in fat quantity (9-31\% of calories) but equal in fat quality (soybean oil) had much lower percentage of 18:2 and higher percentages of de novo synthesized fatty acids in the adipose tissue compared with the dietary fat, as well as a strong positive correlation between adipose tissue $\% 18: 2$ and percent fat calories (21). A pattern of low 18:2 and high de novo fatty 
acids (predominantly 16:0) is also present in the adipose tissue of newborn infants who synthesize most of their fat in utero from maternal carbohydrate $(20,29)$.

The marked decrease in 18:2 and increase in 16:0 in plasma lipids caused by increased synthesis of 16:0 on low fat diets also occur with 16:0-enriched, high fat diets $(30,31)$. This plasma fatty acid pattern, whether produced by increased de novo or dietary 16:0, may have widespread effects on membrane receptor function (32), thrombosis (17), eicosanoid production (17), and DNA transcription via fatty acid responsive regions (33). Low 18:2 and high saturates and/or monounsaturates have been reported in the plasma (34) and adipose tissue $(35,36)$ of free-living subjects who have or who develop coronary artery disease. It is important to know whether increased de novo synthesis of saturated fat contributes to the fatty acid patterns associated with coronary heart disease in epidemiological surveys.

Although the large increase in fatty acid synthesis on the very low fat diet was associated with dramatic changes in the fatty acid composition and concentration of plasma TG, 24-h energy expenditure was nearly identical to predicted requirements. This implied that the absolute rate of conversion of glucose carbon to fatty acid was small. If the TG synthesis rate is assumed to be at the upper reported limit of $25 \mathrm{grams} / \mathrm{d}$ and one half is made from de novo fatty acids, only 12.5 grams of 16:0 would be formed from 40 grams of glucose at an extra energy expense of only $45 \mathrm{kcal} / \mathrm{d}$, or $28 \%$ of the energy content of the glucose (160 kcal) (37). In the course of $25 \mathrm{~d}$, an imbalance as great as $100 \mathrm{kcal} / \mathrm{d}$ may not be reflected by a clear change in body weight. Methods to measure the absolute synthetic rates of both fatty acid and TG are being developed but have been hampered by uncertain size of extraplasma TG pool(s), and other assumptions that may not be met during prolonged low fat, high carbohydrate diets (38).

The nonisotopic and isotopic methods gave the same qualitative differences in de novo lipogenesis between the low fat and high fat diets. However, on the low fat diet, the fraction of de novo fatty acids in total VLDL TG, as measured by the nonisotopic method, was almost twofold higher than the fraction of de novo 16:0 measured by the isotopic method. The lower value by the isotopic method was not due to dilution by unlabeled 16:0 from chylomicrons (no B48) or to comigration of unlabeled closely migrating peaks, such as $16: 1$, on the GCMS. From the shape of the curve of isotopic labeling of 16:0 after prolonged infusions of ${ }^{13} \mathrm{C}$-acetate (not shown), equilibration of labeled 16:0 with the unlabeled TG pool was essentially complete, yet the discrepancy between methods persisted.

To explain the difference between methods, it is possible that there was substantial elongation/desaturation of de novo $16: 0$ to $9 \mathrm{c}-18: 1$ (and/or 18:0, 16:1, 11c-18:1) $(39,40)$ or chainshortening of 18:0 to $16: 0$ (41). Alternatively, it is possible that the decrease in 18:2 was partially due to decreased input or increased output of 18:2 from plasma TG. However, it should be noted that selective fatty acid metabolism was not apparent on the high fat diet, as indicated by the similar fatty acid compositions of the VLDL TG and diet-adipose tissue. Furthermore, there is no definite evidence that large, persistent differences exist in the clearance or incorporation of 16:0 relative to $18: 2$ into VLDL TG in animals $(42)$ or humans $(43,44)$ fed low fat or low 18:2 diets. The evaluation of these possibilities will require studies that simultaneously compare the in vivo metabolism of isotopically labeled 16:0, 18:0, 9c-18:1, and 18:2.
The complex interactions between diet and the mediators that control the rate of fatty acid synthesis have been studied extensively in animals and in tissue culture systems. The relative balance between stimulation by insulin, $\mathrm{T}_{3}$, glucocorticoids, and glucose and inhibition by fatty acids and glucagon is important in a tissue-specific fashion $(5,33,45)$. The half-life of the lipogenic enzymes is $\sim 36-48 \mathrm{~h}$, thus, our finding of a prolonged stimulatory effect on fatty acid synthesis by the low fat diet over $24 \mathrm{~h}$ is consistent with increased enzyme levels and/or hormonal changes that increase substrate flux through the lipogenic pathway. In agreement with other studies (46), our study suggested that the insulin response during the day after meals, but not the fasting insulin, was higher after the low fat compared with the high fat diet, although it greatly varied among subjects. More frequent measurements of day-long insulin, glucose, and glucagon, as well as of insulin sensitivity and glucose disposal, are needed to understand diet-induced differences in human fatty acid synthesis.

These results should be generalized to diets consumed by the general population with caution. Preliminary data from our laboratory indicate that fatty acid synthesis is equally stimulated by very low fat diets with short-chain glucose polymers, as was tested in this study, or with a mixture of simple sugars (glucose, fructose, sucrose, and lactose). However, fatty acid synthesis was much less increased when half of the carbohydrate was starch or a mixture of complex carbohydrates (references 47 and 48, and manuscript in preparation, Hudgins et al.). The type of simple sugar may also be important (49). Oral fructose, unlike glucose, was recently shown to stimulate fatty acid synthesis in humans after a single day of feeding, perhaps because of its direct uptake and rapid phosphorylation by the liver (50).

In conclusion, increased fatty acid synthesis that increases 16:0-enriched, 18:2-depleted TG in plasma is a potential hazard associated with the extreme substitution of dietary fat with sugar. Further studies in different subsets of the population with different amounts and types of carbohydrate are needed to reveal the relevance of these findings to the development of disease.

\section{Acknowledgments}

The excellent technical assistance of Orit Gur-Arieh, Stuart Shiff, Ludmila Malikin, Ellen Murphy, Dave Markell, Katie Tsang, and Yim Dam is much appreciated. We also thank the nursing and dietary staff of the Rockefeller GCRC.

The work was supported by National Institutes of Health GCRC grant M01-RR00102, P30DK26687, PO1CA29502, DK40995, a grant from the Nora Eccles Treadwell Foundation (San Leandro, CA), the Frederick P. Rose Clinical Scholar Award (Dr. Lisa Hudgins), and a Clinical Research Award from the American Diabetes Association (Dr. Marc Hellerstein).

\section{References}

1. Hirsch, J., and R.B. Goldrick. 1964. Serial studies on the metabolism of human adipose tissue. I. Lipogenesis and free fatty acid uptake and release in small aspirated samples of subcutaneous fat. J. Clin. Invest. 43:1776-1792.

2. Sjostrom, L. 1973. Carbohydrate-stimulated fatty acid synthesis de novo in human adipose tissue of different cellular types. Acta Med. Scand. 194:387-404.

3. Angel, A., and G.A. Bray. 1979. Synthesis of fatty acids and cholesterol by liver, adipose tissue and intestinal mucosa from obese and control patients. Eur. J. Clin. Invest. 9:355-362.

4. Barakat, H.A., V.D. McLendon, J.W. Carpenter, R.H.L. Marks, N. Legett, K. O'Brien, and J.F. Caro. 1991. Lipogenic potential of liver from morbidly obese patients with and without non-insulin-dependent diabetes. Metab. Clin. Exp. 40:280-285. 
5. Goodridge, A.G. 1987. Dietary regulation of gene expression: enzymes involved in carbohydrate and lipid metabolism. Annu. Rev. Nutr. 7:157-185.

6. Shillabeer, G., J. Hornford, J.M. Forden, N.C. Wong, and D.C. Lau. 1990. Hepatic and adipose tissue lipogenic enzyme mRNA levels are suppressed by high fat diets in the rat. J. Lipid Res. 31:623-631.

7. Acheson, K.J., Y. Schutz, T. Bessard, K. Anantharaman, J.-P. Flatt, and E. Jequier. 1988. Glycogen storage capacity and de novo lipogenesis during massive carbohydrate overfeeding in man. Am. J. Clin. Nutr. 48:240-247.

8. Hellerstein, M.K., M. Christiansen, S. Kaempfer, C. Kletke, K. Wu, J.S. Reid, K. Mulligan, N.S. Hellerstein, and C.H.L. Shackleton. 1991. Measurement of de novo hepatic lipogenesis in humans using stable isotopes. J. Clin. Invest. 87:1841-1852.

9. Hellerstein, M.K., and R.A. Neese. 1992. Mass isotopomer distribution analysis: a technique for measuring biosynthesis and turnover of polymers. Am. J. Physiol. 263:E988-E1001.

10. Leitch, C.A., and P.J.H. Jones. 1993. Measurement of human lipogenesis using deuterium incorporation. J. Lipid Res. 34:157-163.

11. Faix, D., R. Neese, C. Kletke, S. Wolden, D. Cesar, M. Coutlangus, C. Shackleton, and M. Hellerstein. 1993. Quantification of menstrual and diurnal periodicities in rates of cholesterol and fat synthesis in humans. J. Lipid Res. 34: 2063-2075.

12. Sniderman, A.D., and K. Cianflone. 1993. Substrate delivery as a determinant of hepatic apoB secretion. Arterioscler. Thromb. 13:629-636.

13. Melish, J., N. Le, H. Ginsberg, D. Steinberg, and W.V. Brown. 1980. Dissociation of apoprotein B and triglyceride production in very-low-density lipoproteins. Am. J. Physiol. 239:354-362.

14. Jayakumar, A., M. Tai, W. Huang, W. Al-Feel, M. Hsu, L. Abu-Elheiga, S.S. Chirala, and S.J. Wakil. 1995. Human fatty acid synthase: properties and molecular cloning. Proc. Natl. Acad. Sci. USA. 92:8695-8699.

15. NIH. 1993. National Institutes of Health Consensus Conference: Triglyceride, high-density lipoprotein, and coronary heart disease. J. Am. Med. Assoc. 269:505-510

16. DHHS. 1988. Department of Health and Human Services: Nutrition and Health. Surgeon General's Report.

17. Goodnight, S., W. Harris, W. Connor, and D.R. Illingworth. 1982. Polyunsaturated fatty acids, hyperlipidemia and thrombosis. Arteriosclerosis. 2:87113.

18. Lindgren, F., L. Jensen, and F. Hatch. 1972. The isolation and quantitative analysis of serum lipoproteins. In Blood Lipids and Lipoproteins: Quantitation, Composition, and Metabolism. G. Nelson, editor. John Wiley and Sons, Inc., New York. 221-244.

19. Folch, J., M. Lees, and G. Sloane-Stanley. 1957. A simple method for the isolation and purification of total lipids from animal tissue. J. Biol. Chem. 226:497-509.

20. Hirsch, J., J.W. Farquhar, E.H. Ahrens, M.L. Peterson, and W. Stoffel. 1960. Studies of adipose tissue in man. Am. J. Clin. Nutr. 8:499-511.

21. Ito, Y., L.C. Hudgins, J. Hirsch, and M. Shike. 1991. Adipose tissue fatty acid composition in recipients of long-term total parenteral nutrition (TPN). Am. J. Clin. Nutr. 53:1487-1492.

22. Warnick, G., J. Benderson, and J. Albers. 1982. Dextran sulfate- $\mathrm{Mg}^{2+}$ precipitation procedure for quantitation of high-density-lipoprotein cholesterol. Clin. Chem. 28:1379-1388.

23. Herbert, V., K. Lau, C.W. Gottlieb, and S.J. Bleicher. 1965. Coated charcoal immunoassay of insulin. J. Clin. Endocrinol. \& Metab. 25:1375-1384.

24. Hudgins, L.C., and J. Hirsch. 1991. Changes in abdominal and gluteal adipose tissue fatty acid compositions in obese subjects after weight gain and weight loss. Am. J. Clin. Nutr. 53:1372-1377.

25. Phinney, S.D., J.S. Stern, K.E. Burke, A.B. Tang, G. Miller, and R.T. Holman. 1994. Human subcutaneous adipose tissue shows site-specific differences in fatty acid composition. Am. J. Clin. Nutr. 60:725-729.

26. Ahrens, E.H., and N. Spritz. 1963. Further studies on fat and carbohydrate-induced lipemia in man. Reduction of lipemia by feeding fat. In Biochemical Problems of Lipids. A.C. Frazer, editor. Elsevier Publishing Company, Amsterdam. 304-312.

27. Bierman, E.L., D. Porte, D.D. O’Hara, M. Schwartz, and F.C. Wood.
1965. Characterization of fat particles in plasma of hyperlipemic subjects maintained on fat-free high-carbohydrate diets. J. Clin. Invest. 44:261-270.

28. Wene, J.D., W.E. Connor, and L. DenBesten. 1975. The development of essential fatty acid deficiency in healthy men fed fat free diets intravenously and orally. J. Clin. Invest. 56:127-134.

29. Sweeney, M.J., J.N. Etteldorf, L.J. Throop, D.L. Timma, and E.L. Wrenn. 1963. Diet and fatty acid distribution in subcutaneous fat and in the cholesterol-triglycerides fraction of serum of young infants. J. Clin. Invest. 42:1-9.

30. Spritz, N., and M.A. Mishkel. 1969. Effects of dietary fats on plasma lipids and lipoproteins: an hypothesis for the lipid-lowering effect of unsaturated fatty acids. J. Clin. Invest. 48:78-86.

31. Baudet, M.F., O. Esteva, B. Delplanque, N. Winchene, and B. Jacotot. 1980. Effects of three dietary fats on plasma lipids and lipoproteins in fasting and post-prandial humans after a short-term diet. Lipids. 15:216-223.

32. Clandinin, M.T., S. Cheema, C.J. Field, M.L. Garg, J. Venkatraman, and T.R. Clandinin. 1991. Dietary fat: exogenous determination of membrane structure and cell function. FASEB (Fed. Am. Soc. Exp. Biol.) J. 5:2761-2769.

33. Clarke, S.D., and D.B. Jump. 1994. Dietary polyunsaturated fatty acid regulation of gene transcription. Annu. Rev. Nutr. 14:83-98.

34. Siguel, E.N. 1994. Altered fatty acid metabolism in patients with angiographically documented coronary artery disease. Metab. Clin. Exp. 43:982-993.

35. Riemersma, R.A., D.A. Wood, S. Butler, R.A. Elton, M. Oliver, M. Salo, T. Nikkari, E. Vartiainen, P. Puska, F. Gey, et al. 1986. Linoleic acid content in adipose tissue and coronary heart disease. Br. Med. J. 292:1423-1427.

36. Wood, D.A., R.A. Riemersma, S. Butler, M. Thomson, C. Macintyre, R.A. Elton, and M.F. Oliver. 1987. Linoleic and eicosapentaenoic acids in adipose tissue and platelets and risk of coronary heart disease. Lancet. (Jan. 24): 177-183.

37. Flatt, J.P. 1978. The biochemistry of energy expenditure. Recent Adv. Obes. Res. 2:211-227.

38. Hellerstein, M.K., R. Neese, and J.-M. Schwartz. 1993. Model for measuring absolute rates of hepatic de novo lipogenesis and reesterification of free fatty acids. Am. J. Physiol. 265:E814-E820.

39. Ntambi, J.M. 1992. Dietary regulation of stearoyl-coA desaturase 1 gene expression in mouse liver. J. Biol. Chem. 267:10925-10930.

40. Elovson, J. 1965. Conversions of palmitic and stearic acid in the intact rat. Biochem. Biophys. Acta. 106:291-303.

41. Emken, E.A., R.O. Adlof, W.K. Rohwedder, and R.M. Gulley. 1993. Influence of linoleic acid on desaturation and uptake of deuterium-labeled palmitic and stearic acids in humans. Biochim. Biophys. Acta. 1170:173-181.

42. Toorop, A.I., D.R. Romsos, and G.A. Leveille. 1979. The metabolic fate of dietary 1-[14C]palmitate in meal-fed rats. Proc. Soc. Exp. Biol. Med. 160: 312-316.

43. Nestel, P.J., and P. Barter. 1971. Metabolism of palmitic and linoleic acids in man: differences in turnover and conversion to glycerides. Clin. Sci. 40: $345-350$.

44. Jones, P.J.H., and D.A. Schoeller. 1988. Polyunsaturated:saturated ratio of diet influences energy substrate utilization in the human. Metab. Clin. Exp. 37:145-151.

45. Moustaid, N., R.S. Beyer, and H.S. Sul. 1994. Identification of an insulin response element in the fatty acid synthase promoter. J. Biol. Chem. 269:56295634

46. Coulston, A.M., G.C. Liu, and G.M. Reaven. 1983. Plasma glucose, insulin and lipid responses to high-carbohydrate low-fat diets in normal humans. Metab. Clin. Exp. 32:52-56.

47. Hudgins, L.C., M.K. Hellerstein, C. Seidman, J. Diakun, and J. Hirsch. 1993. Carbohydrate induced lipogenesis: a potential adverse effect of low fat diets. Circulation. 88(Suppl. 2):I-317.

48. Hudgins, L.C. 1995. Decreased fatty acid synthesis after substitution of dietary starch for sugar. Circulation. 92(Suppl.):I-157.

49. Frayn, K., and S. Kingman. 1995. Dietary sugars and lipid metabolism in humans. Am. J. Clin. Nutr. 62(Suppl.):250S-263S.

50. Schwartz, J., R. Neese, C. Shackelton, and M. Hellerstein. 1993. De novo lipogenesis during fasting and oral fructose in lean and obese hyperinsulinemic subjects. Diabetes. 42(Suppl. 1):39A. 